\title{
Papilloedema and hepatic dysfunction apparently induced by perhexiline maleate (Pexid)
}

\author{
A B ATKINSON, D MCAREAVEY, G TROPE* \\ From the MRC Blood Pressure Unit, Western Infirmary, Glasgow G11 6NT, Scotland
}

SUMMARY A patient developed papilloedema and hepatic dysfunction while being treated with perhexiline maleate. These later regressed when the drug was withdrawn. Patients should be monitored for these potentially serious side-effects while on this drug.

Perhexiline maleate (Pexid), a drug introduced for the prophylaxis of angina pectoris, has been implicated in the development of peripheral neuropathy, ${ }^{1}$ ataxia, ${ }^{2}$ myopathy, ${ }^{3}$ and papilloedema ${ }^{4}$ We describe here a patient who developed papilloedema and abnormal liver function while on the drug, these abnormalities subsiding after it was withdrawn.

\section{Case report}

A 48-year-old man presented in September 1978 with a complaint of staggering to the right, nausea, vomiting, and early morning headaches for six weeks. There was no history of recent excessive alcohol intake. He was known to have been severely hypertensive since 1966. Enucleation of the left eye had been performed after trauma in 1975. He had had severe angina pectoris from 1977, for which coronary artery bypass surgery was performed in September 1977. After a myocardial infarction in December 1977, the angina, which had been relieved by operation, recurred, and in April 1978 perhexiline maleate (Pexid) $200 \mathrm{mg}$ twice daily was prescribed in addition to the then current therapy of bumetanide $2 \mathrm{mg}$ daily, amiloride $10 \mathrm{mg}$ twice daily, sorbitrate $10 \mathrm{mg}$ four times daily, propranolol $320 \mathrm{mg}$ twice daily, and hydralazine $25 \mathrm{mg}$ twice daily.

On initial examination the blood pressure was $150 / 90 \mathrm{mmHg}$. There was no evidence of cardiac failure. He had incoordination of the right leg on heel-shin testing, and unsteadiness of gait, tending to stagger to the right. Papilloedema was seen in the right eye. Fluorescein angiography disclosed distinct leakage of fluorescein from the disc,

\footnotetext{
*Tennent Institute of Ophthalmology, University of Glasgow Western Infirmary, Glasgow.
}

especially in the later phases from five minutes onwards (Fig.). Visual field testing showed an enlarged blind spot. His visual acuity, however, remained excellent at $6 / 5$ (corrected). Serum asparate transaminase (AST), alanine transaminase (ALT), and lactate dehydrogenase (LDH) were obviously raised at 585,1185 , and $890 \mathrm{U} / 1$; these had been 16,26 , and $375 \mathrm{U} / 1$, respectively, in December 1977 (normal ranges $<42$, $<55$, and $<500$ ). Hepatitis B antigen was negative. Haemoglobin was $16 \cdot 1 \mathrm{~g} / \mathrm{dl}$. Serum electrolytes and urea were normal. Electrocardiograms showed no change from previous records. Skull $x$-ray, electroencephalogram, isotope brain scan, and computerised axial tomography of the brain were normal.

As his new symptoms and signs were thought probably to result from perhexiline maleate toxicity, this drug was withdrawn. Six weeks later the patient reported improvement of symptoms, the papilloedema and ataxia were less distinct, and a repeat fluorescein angiogram showed less leakage of dye from the disc (Fig.). AST, ALT, and LDH had all become normal $(21,19$, and $375 \mathrm{U} / 1$, respectively).

\section{Discussion}

One previous case of hepatic dysfunction together with papilloedema has been described in a patient receiving perhexiline, ${ }^{2}$ and several cases of papilloedema have been described in association with the drug. ${ }^{134}$ In our patient the symptoms and signs improved within six weeks of withdrawal of the drug. Perhexiline, therefore, seems likely to have been the offending agent.

The mechanisms involved are unclear. In one case a raised cerebrospinal fluid (CSF) pressure was shown by lumbar puncture. ${ }^{2}$ However, in a more recent report the CSF pressure was normal but the 


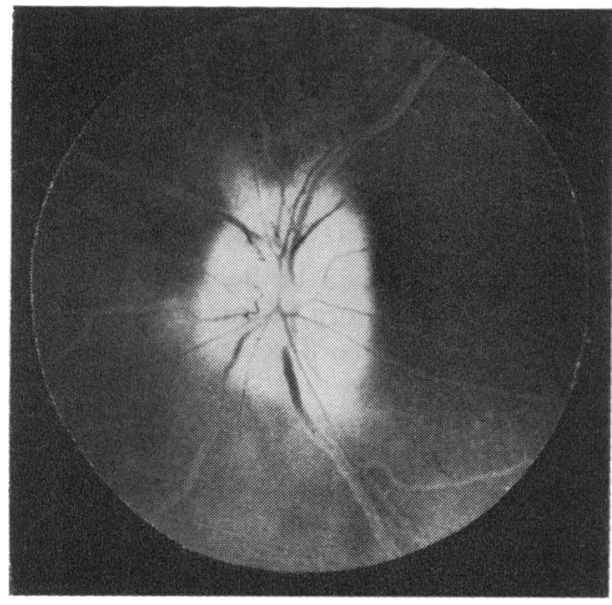

a

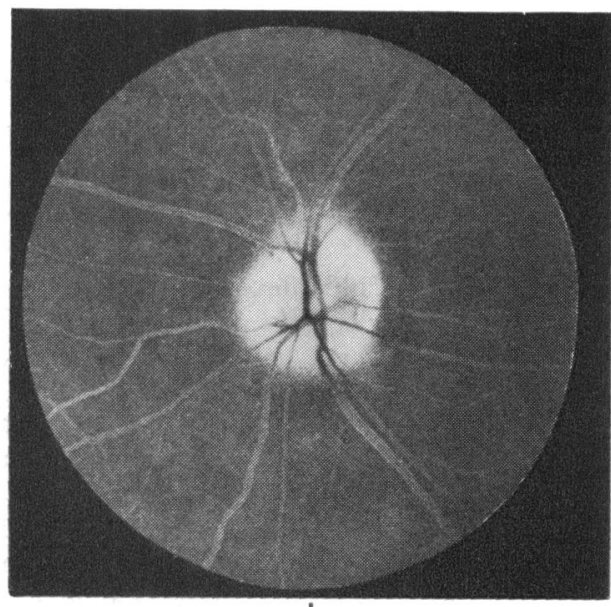

b

Fig. Fluorescein angiograms of the fundus shown at 10 minutes after injection of dye: (a) in September 1978 while on perhexiline maleate shows gross leakage of dye, while (b) taken in November 1978 shows almost complete resolution.

protein concentration raised. ${ }^{4}$ Lumbar puncture was not performed in our patient because of the possible risk involved. The cause of the hepatic dysfunction also remains undetermined.

In the present case, symptoms began four months after the treatment was started. This is sooner than in previous reports, ${ }^{1-4}$ in which patients developed symptoms after at least 10 months' therapy. The more rapid onset here may have been a result of our using the highest recommended dose. The clinical features of toxicity normally resolve, as in the present case, but in one previous patient visual acuity was still impaired two years after stopping the drug. ${ }^{2}$

We suggest that perhexiline maleate be prescribed only after other medical treatments for angina have failed and that, when it is given, hepatic function tests and ophthalmological screening should be performed at regular intervals.

We should like to thank Drs A F Lever and J I S Robertson for permission to report this patient who was under their care and also for their help and encouragement in writing this paper. We should also like to thank Professor J A Simpson who supervised the neurological investigations.

\section{References}

'Bousser MG, Bouche P, Brichard C, Herrman G. Neuropathies périphériques au maleate de perhexiline. A propos de 7 observations. Coeur Med Interne 1976; 15(2): $181-8$.

${ }^{2}$ Stephens WP, Eddy JD, Parsons LH, Singh SP. Raised intracranial pressure due to perhexiline maleate. Br Med f 1978; 1: 21.

${ }^{3}$ Tomlinson IW, Rosenthal FD. Proximal myopathy after perhexiline maleate therapy. $\mathrm{Br}$ Med $\mathcal{f} 1977$; 1 : 1319-20.

${ }^{4}$ Hutchinson WM, Williams J, Gawler J. Papilloedema in patients taking perhexiline maleate. $\mathrm{Br} \operatorname{Med} \mathcal{F} 1978$; 1: 305 .

Requests for reprints to $\mathrm{Dr} A \mathrm{~B}$ Atkinson, MRC Blood Pressure Unit, Western Infirmary, Glasgow G11 6NT. 